\title{
A Communal Sign Post of Snow Leopards (Panthera uncia) and Other Species on the Tibetan Plateau, China
}

\author{
Juan Li, ${ }^{1}$ George B. Schaller, ${ }^{2}$ Thomas M. McCarthy, ${ }^{3}$ Dajun Wang, \\ Zhala Jiagong, ${ }^{4}$ Ping Cai, ${ }^{5}$ Lamao Basang, ${ }^{6}$ and Zhi Lu ${ }^{1,4}$ \\ ${ }^{1}$ Center for Nature and Society, College of Life Sciences, Peking University, Beijing 100871, China \\ ${ }^{2}$ Panthera and Wildlife Conservation Society, 8 West 40th Street, 18th Floor, New York, NY 10018, USA \\ ${ }^{3}$ Snow Leopard Program, Panthera, 8 West 40th Street, 18th Floor, New York, NY 10018, USA \\ ${ }^{4}$ Shan Shui Conservation Center, Beijing 100871, China \\ ${ }^{5}$ Wildlife Conservation and Management Bureau, Qinghai Forestry Department, Xining 810008, Qinghai, China \\ ${ }^{6}$ Sanjiangyuan National Nature Reserve, Qinghai Forestry Department, Xining 810008, Qinghai, China
}

Correspondence should be addressed to Juan Li; lijuan924@gmail.com

Received 29 September 2012; Accepted 13 November 2012

Academic Editor: Rafael Riosmena-Rodríguez

Copyright (C) 2013 Juan Li et al. This is an open access article distributed under the Creative Commons Attribution License, which permits unrestricted use, distribution, and reproduction in any medium, provided the original work is properly cited.

\begin{abstract}
The snow leopard is a keystone species in mountain ecosystems of Central Asia and the Tibetan Plateau. However, little is known about the interactions between snow leopards and sympatric carnivores. Using infrared cameras, we found a rocky junction of two valleys in Sanjiangyuan area on the Tibetan Plateau where many mammals in this area passed and frequently marked and sniffed the site at the junction. We suggest that this site serves as a sign post to many species in this area, especially snow leopards and other carnivores. The marked signs may also alert the animals passing by to temporally segregate their activities to avoid potential conflicts. We used the Schoener index to measure the degree of temporal segregation among the species captured by infrared camera traps at this site. Our research reveals the probable ways of both intra- and interspecies communication and demonstrates that the degree of temporal segregation may correlate with the degree of potential interspecies competition. This is an important message to help understand the structure of animal communities. Discovery of the sign post clarifies the importance of identifying key habitats and sites of both snow leopards and other species for more effective conservation.
\end{abstract}

\section{Introduction}

The snow leopard (Panthera uncia), an endangered species listed in IUCN Red List [1], occurs in remote and rugged mountains across Central Asia and the Tibetan Plateau [2]. As a keystone species, this cat has an important role in these mountain ecosystems [3]. But with only an estimated population of 3500-7000 remaining, the snow leopard generally occurs at low densities. Poaching, retaliatory killing due to livestock-snow leopard conflict, decimation of prey, and habitat degradation have all contributed to its rarity [2]. Most studies of snow leopard have focused on its habitat $[4,5]$ and food habits [6-8], whereas little is known about the interaction of snow leopards and their sympatric species.
Olfactory and visual signals are known as crucial mediators for intraspecies communication. Mammals, especially solitary species, use these signals to advertise reproductive status, recognize sex, identify individuals, establish territory and so on $[9,10]$. Communal sign posts have, for example, been found in snow leopard [11], giant panda (Ailuropoda melanoleuca) [12], and American black bear (Ursus americanus) [13] habitats. However, previous studies did not describe interspecies interactions at such locations.

In this study, we discovered a site sniffed and marked by snow leopards and several other carnivores, a sign post. White et al. (2003) used the term "bulletin board" to describe such a site used by pandas [14]. There, one animal leaves a message (such as feces or urine), followed by another animal 
which sees or smells this message. Such communication could help different species avoid direct confrontation and may lead to temporal segregation [15].

To identify the interaction between snow leopards and sympatric species, we recorded the date, time, and corresponding behavior of the animals passing by this site with infrared camera traps. The analysis of these behaviors showed that snow leopards and other carnivores frequently marked and sniffed at this site, indicating the site functions as a sign post. Our data also showed that the sympatric carnivores were temporally segregated in both annual and daily activity patterns. The degree of temporal segregation may be related to the degree of competition among the species.

\section{Materials and Methods}

2.1. Study Area. The field study was conducted in Suojia Township in Yushu Prefecture (Figure 1), the core area of the Sanjiangyuan National Nature Reserve, Qinghai Province, China. This region has a high density of snow leopards $[6,16]$. The climate is typically windy and dry. The average annual temperature is $-4^{\circ} \mathrm{C}$ (range from $-12^{\circ} \mathrm{C}$ to $-20^{\circ} \mathrm{C}$ in January and $8^{\circ} \mathrm{C}$ to $-10^{\circ} \mathrm{C}$ in July), and the average annual precipitation is $150-420 \mathrm{~mm}$ [17]. Alpine meadow is the major vegetation type, consisting of mainly a layer up to $30 \mathrm{~cm}$ thick of turf densely covered with sedge (Kobresia spp.). In addition to the snow leopard, the main mammal species in this area include the gray wolf (Canis lupus), the Tibetan brown bear (Ursus arctos), the Eurasian lynx (Lynx lynx), the red fox (Vulpes vulpes), the Tibetan fox (Vulpes ferrilata), Pallas's cat (Otocolobus manul), the stone marten (Martes foina), the blue sheep (Pseudois nayaur), the Himalayan marmot (Marmota himalayana), the plateau pika (Ochotona curzoniae), the large-eared pika (Ochotona macrotis), and various small rodents [17].

2.2. Camera Trapping. From January 1,2011 to December 31, 2011, one Reconyx (HC500 HyperFireTM) passive infrared camera (Reconyx Inc., USA) was installed $35 \mathrm{~cm}$ above ground beside an overhanging rock with several snow leopard scrapes and carnivore feces (site SJ001 in Figure 1). The camera worked without delay between each consecutive exposure. Every time animals triggered the camera, ten continuous images were captured. The camera was checked about every ten days to ensure the angle remained consistent and batteries were charged. No bait or scent lure was used. In the same way, another 15 infrared cameras were placed at 15 sites from late April 2011 onward. Unfortunately, only cameras on five sites worked properly for around six months, and these data are included here (site SJ002, SJ004, SJ008, SJ010, and SJ012 in Figure 1). Other cameras were lost or damaged.

The behaviors of carnivores were divided into three categories: sniffing (receiving information), marking (sending information), and others. Sniffing behavior was defined as smelling the ground or rock. And the marking behavior included behaviors such as scraping, cheek rubbing, back rubbing, spraying, urinating, or defecating. Dogs were included only when they were out on their own, not when they followed people.

2.3. Data Analysis. Camera trap data are usually analyzed by grouping detections occurring within ten or thirty minutes into one capture $[18,19]$. However, this method has two flaws. The first flaw is that the time frame used to group the detections is artificial. Neither ten minutes nor thirty minutes has a clear biological explanation. The second flaw is that grouping detections occurring within a period of time into one capture decrease data accuracy, a method less suitable for analysis of daily activity patterns. Therefore, we define a single capture as one individual (including every individual within a group) passing by the camera once. To build the daily activity curves, we averaged the number of captures within the adjacent two hours as the number of captures for each species. For example, the capture number at 3:00 is the 2hour average of captures from 2:00 to 3:59. The annual and daily overlap indexes between two species were calculated according to the formula of Schoener [20].

To summarize, we used the following formulas in our study.

(1) Activity index of time point $A=$ (captures at this time point)/(captures at the whole time frame).

(2) Capture $=\sum_{i=1}^{n}$ Individuals $(n=$ number of times animal passes by the camera).

(3)

$$
\alpha_{i j}=1-\frac{1}{2} \sum_{a=1}^{n}\left|p_{i a}-p_{j a}\right|,
$$

where $\alpha_{i j}$ is the overlap index of temporal niche between species $i$ and species $j, p_{i a}$ and $p_{j a}$ are the proportions of $a$ th month (for annual overlap index) or hour (for daily overlap index) used by species $i$ and species $j$, respectively.

(4) Total overlap index $=$ Annual overlap index $\times$ Daily overlap index.

We employed the software $R$ to do hierarchical cluster analysis of the pairwise total overlap index with average linkage method and generated a cluster dendrogram [21].

We did not include marmot, pika, and stone marten in these analyses because they were too small for our camera to detect with its $35 \mathrm{~cm}$ height above ground, or too infrequently recorded for analysis.

\section{Results}

3.1. Camera Trap Captures. In 365 trap days from January 1 , 2011 through December 31, 2011, we obtained 485 captures of carnivores and 1100 captures of herbivores at the site SJ001 (Figure 1), including snow leopards (145 captures), gray wolves (106), domestic dogs (73), brown bears (14), red foxes (81), Tibetan foxes (44), Pallas's cats (16), stone martens (6), blue sheep (891), and livestock (209) (Table 1, Figure 2). Snow leopards were the most frequently photographed carnivores, 


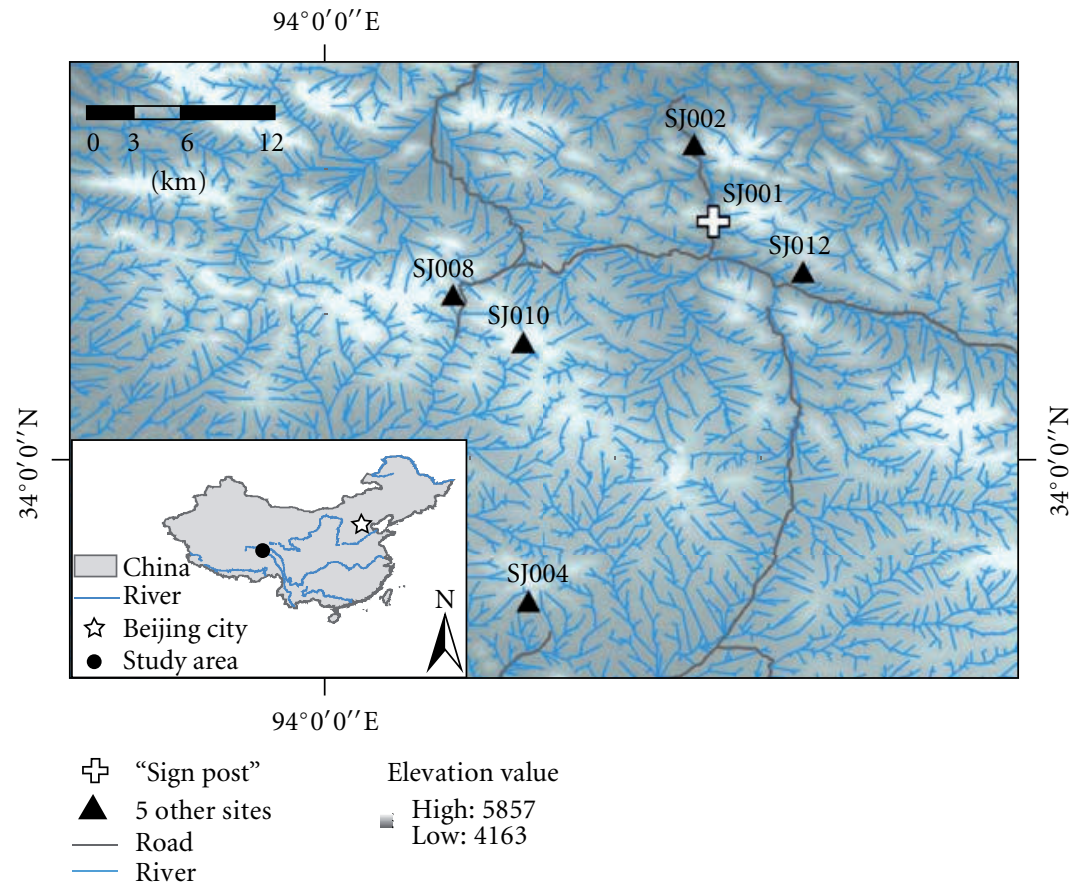

FIgURE 1: Locations of camera traps in Suojia Township in Yushu Prefecture, Qinghai Province, China.

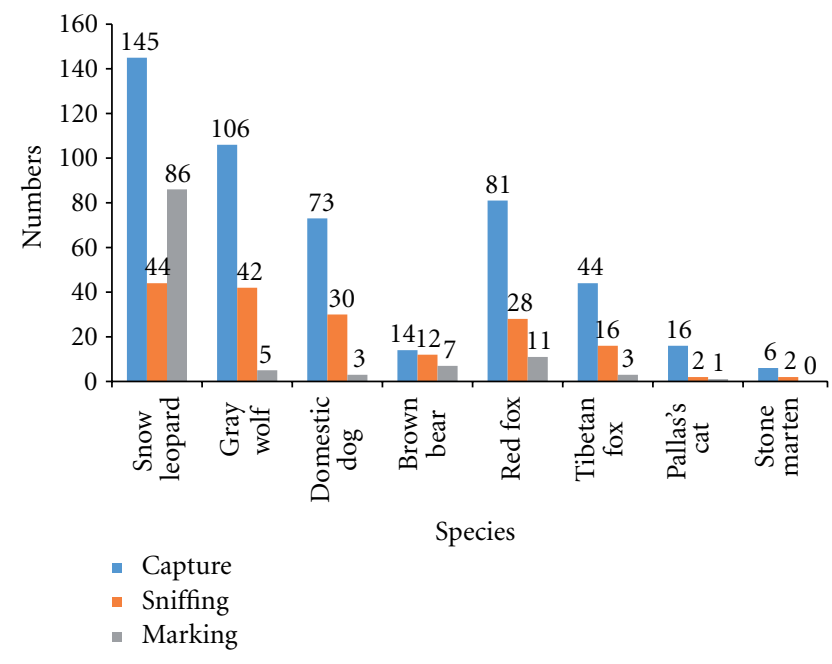

FIGURE 2: Camera trap captures of each carnivore species with sniffing and marking behaviors on the communal sign post.

and we identified six adults and one cub. As for sympatric carnivores, no fewer than five brown bears and six wolves were identified. We were unable to discriminate between the individuals of red foxes (including one young) or Tibetan foxes. The species photographed represented almost all the carnivores found in this area except the lynx and other small mustelids. The captures of camera traps from 5 other sites will be used for comparison in discussion section.

3.2. Behavior. Most carnivores did not just pass by the site SJ001 but spent time sniffing and marking it (Table 1, Figure
2). Snow leopards marked most actively, doing so in 86 out of 145 captures. Wolves marked approximately ten meters from this camera, but from October to December they began to mark the ground near by it. Dogs also sniffed here frequently. Brown bears sniffed this site almost every time they passed and often rubbed their back. Red and Tibetan foxes both seemed to prefer to sniff more than to mark.

3.3. Activity Patterns. Among the large carnivores, snow leopards visited this site (SJ001) throughout the year, their annual activity curve peaking in February (Figure 3(a)). In contrast, brown bears occurred mainly in May and October, and wolves appeared to be most active at this site in February and October. Domestic dogs showed a peak in winter (Figure $3(\mathrm{a})$ ). As for daily activity patterns, snow leopards were active at this site throughout the night with a slightly crepuscular trend. Wolves passed by at noon and dusk, whereas brown bears only appeared at the rock before dawn (Figure 3(b)).

Among the small carnivores, the annual activity pattern of Tibetan foxes was very similar to that of brown bears, while red foxes passed by throughout the year (Figure 4(a)). Daily patterns showed that red foxes typically visited only at night, whereas Tibetan foxes and Pallas's cats came here throughout the day (Figure 4(b)).

The herbivores photographed at this site were livestock (only domestic yaks at this site) and blue sheep. Livestock passed by this site after 8:00 AM and returned before 2:00 PM, their activity pattern depending on the herders (Figure 5(a)). Blue sheep appeared to avoid livestock by appearing at this site before 10:00 AM and after 2:00 PM, but never at night (Figure 5(b)). 
TABLE 1: Numbers of captures, sniffing, and marking behavior of each species captured by camera trapping at the communal sign post.

\begin{tabular}{|c|c|c|c|c|c|c|c|}
\hline Group & English name & Latin name & $\mathrm{IUCN}^{1}$ & $\mathrm{CN}^{2}$ & Capture & Sniffing & Marking \\
\hline \multirow{4}{*}{ Large carnivores } & Snow leopard & Panthera uncia & $\mathrm{EN}$ & I & 145 & 44 & 86 \\
\hline & Gray wolf & Canis lupus & LC & II & 106 & 42 & 5 \\
\hline & Domestic dog & Canis lupus & & & 73 & 30 & 3 \\
\hline & Brown bear & Ursus arctos & $\mathrm{LC}$ & II & 14 & 12 & 7 \\
\hline \multirow{4}{*}{ Small carnivores } & Red fox & Vulpes vulpes & LC & - & 81 & 28 & 11 \\
\hline & Tibetan fox & Vulpes ferrilata & LC & - & 44 & 16 & 3 \\
\hline & Pallas's cat & Otocolobus manul & NT & II & 16 & 2 & 1 \\
\hline & Stone marten & Martes foina & LC & II & 6 & 2 & 0 \\
\hline \multirow{2}{*}{ Herbivores } & Blue sheep & Pseudois nayaur & LC & II & 891 & NA & NA \\
\hline & Domestic yak & Bos mutus & & & 209 & NA & NA \\
\hline
\end{tabular}

${ }^{1}$ IUCN endangered species category (Red List): EN: endangered, NT: near threatened, LC: least concern.

${ }^{2}$ Category of protected wildlife species under China’s Wildlife Protection Law, - : means not listed.

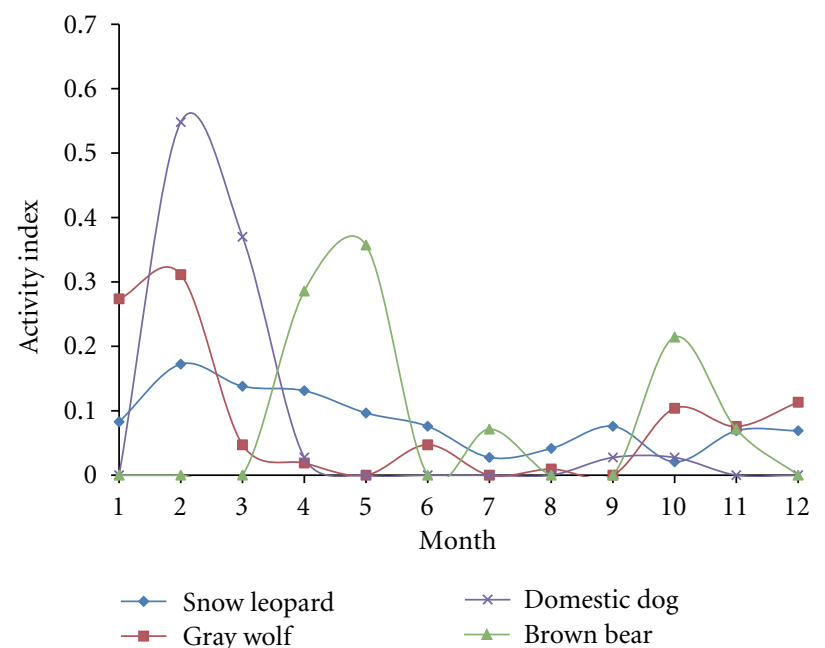

(a)

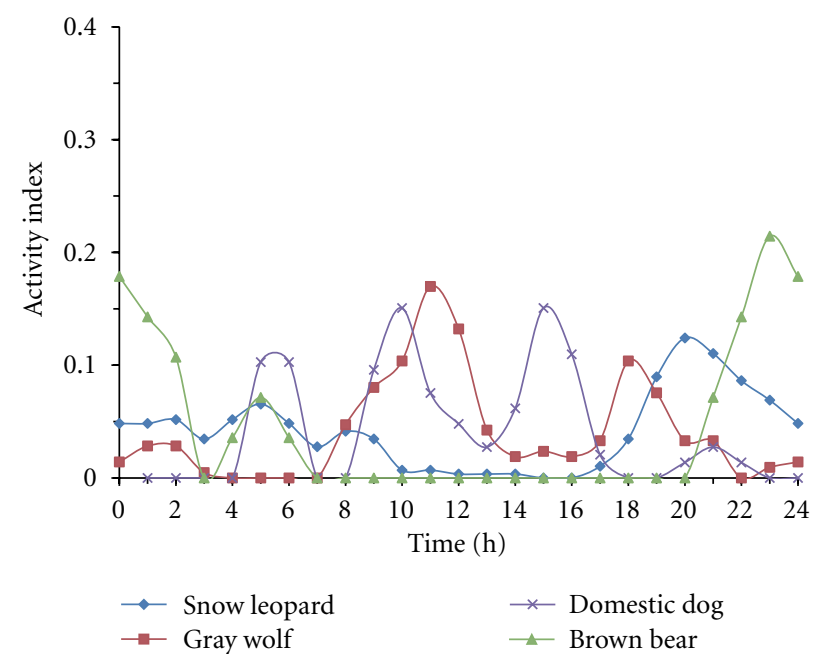

(b)

FIGURE 3: (a) Annual activity patterns and (b) daily activity patterns of large carnivores on the communal sign post. Snow leopard $(n=145)$, gray wolf $(n=106)$, domestic $\operatorname{dog}(n=73)$, and brown bear $(n=14)$ are included.

\section{Discussion}

4.1. Sign Post. Compared with the captures of 5 other cameras placed nearby (Figure 1), the number of snow leopards captured at site SJ001 was much greater (see in Table 2). This difference indicates that this site had special relevance for intraspecies communication in this area. Additionally, the diversity of carnivore species photographed was the highest, implying that this site might also serve as a focal point for interspecies communication (see in Table 2). Previous studies have showed that mammals select conspicuous objects at major traffic hubs to communicate with each other. For example, snow leopards prefer to mark at mountain passes, cliff bases, confluence of rivers, and other conspicuous places $[4,22]$. Brown bears tend to mark along travel routes [23], whereas wolves prefer crossroads [24, 25]. This site is located at a juncture of two major valleys, with an overhanging rock at the base of a cliff. Animals traveling along these valleys pass by here, and the rock is at an appropriate height for depositing scent and rubbing. Whereas, other 5 sites are not located at crossroads. Therefore, it is not surprising that this site is favored by so many carnivore species and serves as a communal sign post.

4.2. Temporal Segregation. Many mammals shared this sign post, especially the carnivores which sniffed and marked it frequently. In addition, carnivores prey on herbivores, and they also prey on each other; and age, size, and patterns of grouping largely determine the outcome of such interactions $[26,27]$. Temporal segregation is an important mechanism for these species to coexist and avoid direct confrontation [28]. To understand this temporal segregation, we first analyzed the probable factors affecting annual and daily activity patterns of the different species and then combined the pairwise annual and daily overlap indexes into a cluster dendrogram to show their interrelationship. 


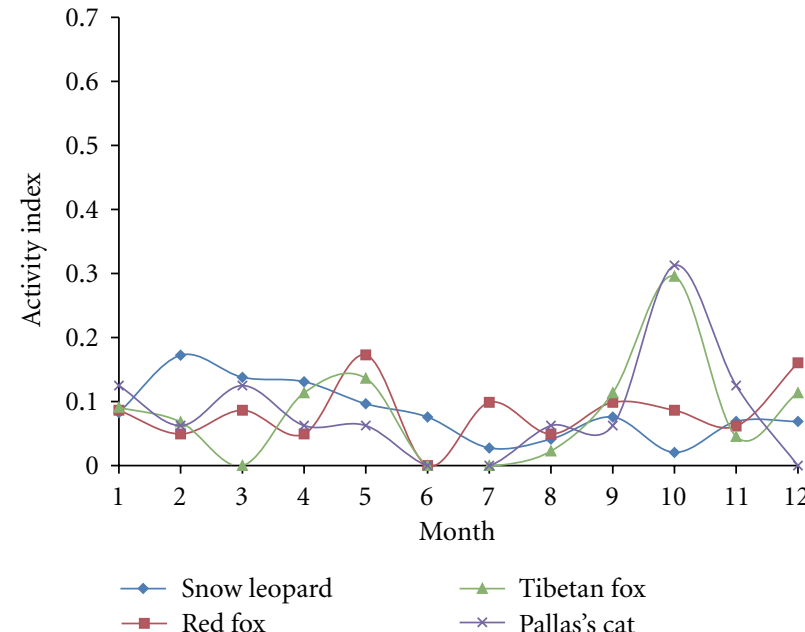

(a)

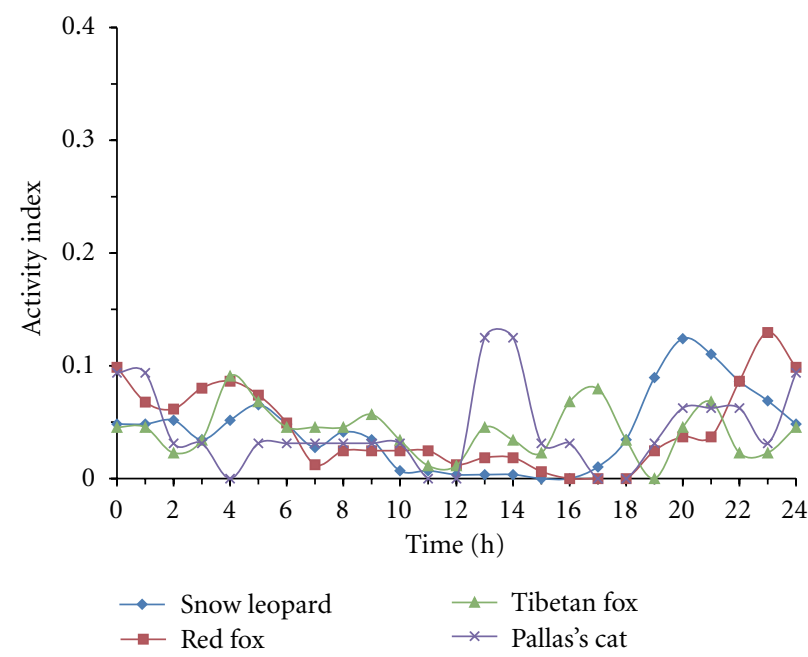

(b)

FIgURE 4: (a) Annual activity patterns and (b) daily activity patterns of snow leopard $(n=145)$ and small carnivores on the communal sign post. Red fox $(n=81)$, Tibetan fox $(n=44)$, and Pallas's cat $(n=16)$ are included.

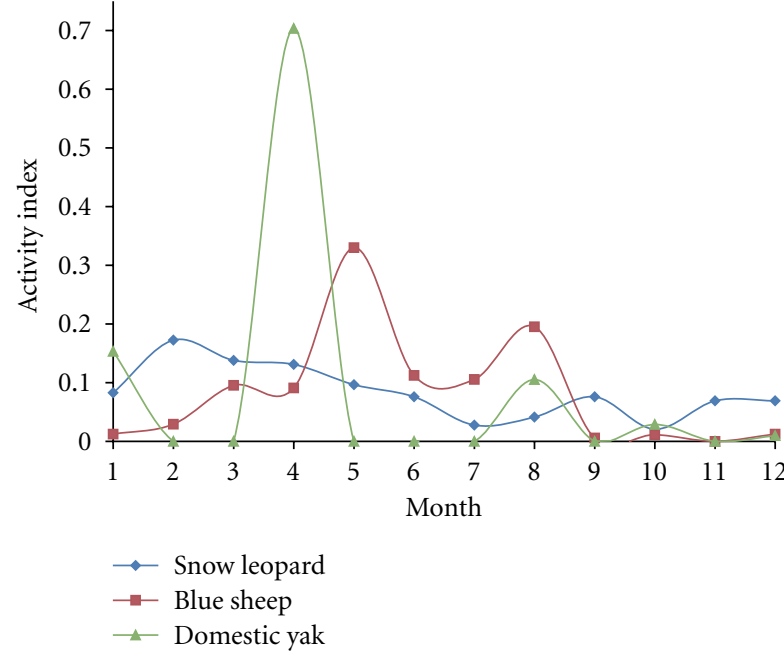

(a)

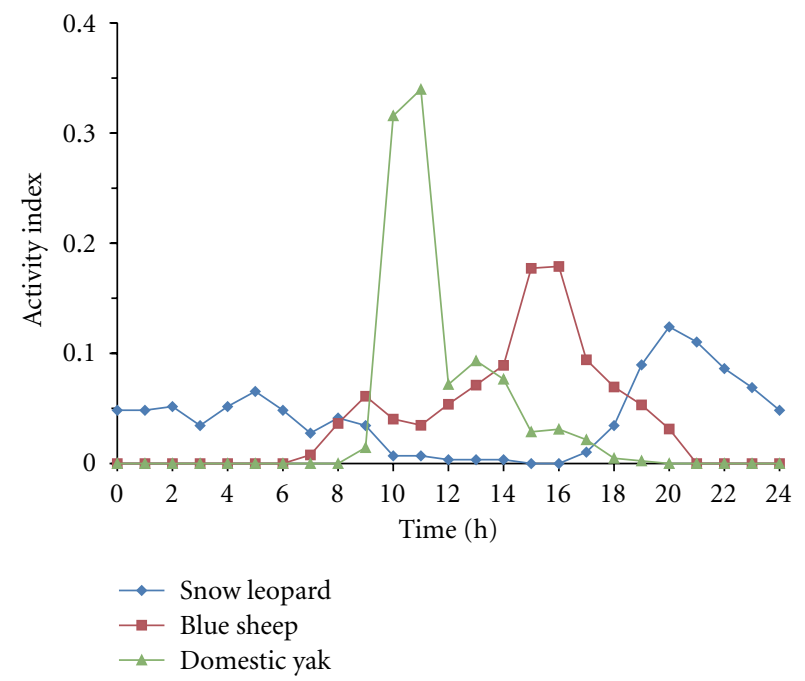

(b)

Figure 5: (a) Annual activity patterns and (b) daily activity patterns of the snow leopard $(n=145)$ and herbivores on the communal sign post. Blue sheep $(n=891)$ and livestock $(n=209)$ are included.

Annual activity patterns are, to a large extent, determined by the natural cycles and somewhat different habitat preferences of species. Snow leopards, for example, remain in steep rocky terrains the whole year, but they are slightly more active in the February mating season when they may roam widely to find a mate. Wolves prefer to live in less precipitous terrains [29]. The activity peak in February may be due to their mating season, but we have no explanation for the October one. Bears apparently mate mainly in May and June and hibernate from about late October to early March, according to our preliminary data. We found several caves in which bears had hibernated near this communal sign post. Brown bears are said to be much more active before hibernation to lay on fat [30]. Consequently, the annual activity curve of these bears shows peaks in May and in October.

Compared to annual activity patterns, the daily ones appeared to be more flexible. Affected by various factors, among them hunting and other human activities, animals may become more nocturnal or seek different habitats. The interactions among the various species may also affect it. To be specific, the snow leopard is active mainly at night, and its prey, the blue sheep which is active around this site only during the day, showed a conspicuous difference of their activity patterns. Wolves tend to be nocturnal, with activity 
Cluster dendrogram

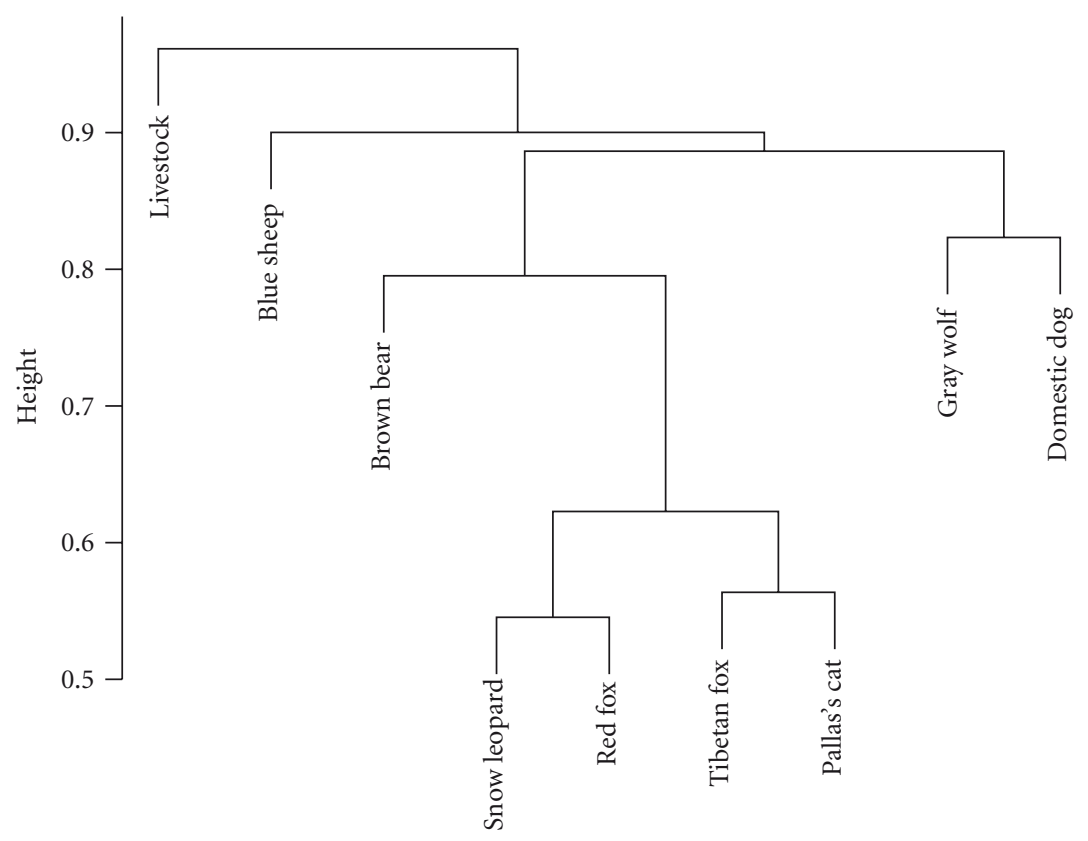

FIGURE 6: Cluster analysis dendrogram of pairwise total overlap indexes. It shows the interrelationship of the nine species' activity patterns at the communal sign post. Height represents the distance linkage between clusters.

TABle 2: Number of captures of each species on six sites from May 1 to October 31, 2011.

\begin{tabular}{|c|c|c|c|c|c|c|c|}
\hline Group & Species & SJ001 $^{1}$ & SJ002 & SJ004 & SJ008 $^{2}$ & SJ010 & SJ012 \\
\hline \multirow{4}{*}{ Large carnivores } & Snow leopard & 49 & 14 & 8 & 6 & 7 & 36 \\
\hline & Gray wolf & 17 & 2 & 0 & 0 & 0 & 1 \\
\hline & Domestic dog & 4 & 0 & 0 & 1 & 0 & 0 \\
\hline & Brown bear & 9 & 0 & 0 & 0 & 3 & 1 \\
\hline \multirow{4}{*}{ Small carnivores } & Red fox & 41 & 5 & 14 & 46 & 7 & 2 \\
\hline & Tibetan fox & 25 & 8 & 0 & 0 & 0 & 0 \\
\hline & Pallas's cat & 8 & 25 & 7 & 9 & 2 & 1 \\
\hline & Stone marten & 2 & 0 & 1 & 2 & 0 & 0 \\
\hline \multirow{2}{*}{ Herbivores } & Blue sheep & 677 & 188 & 365 & 242 & 10 & 69 \\
\hline & Livestock & 28 & 81 & 46 & 184 & 0 & 0 \\
\hline \multicolumn{2}{|c|}{ Total } & 860 & 323 & 441 & 490 & 29 & 110 \\
\hline
\end{tabular}

The communal sign post.

${ }^{2}$ The camera did not work from July 28 to August 9 because batteries were dead.

levels peaking at dawn and dusk in other areas [31, 32], whereas their activity patterns were diurnal at the communal sign post. This could be due to avoidance between wolves and snow leopards, causing one species shift its activity pattern into an opposite phase [28]. Brown bears only passed by this site at night with peaks at 23:00 and 5:00 as shown in our few records. We found that bears would follow snow leopards to scavenge on their kills, and this is perhaps one reason their daily activity patterns are similar.

To measure the degree of temporal segregation between any two species at this communal sign post, we introduced the total overlap index (see Section 2), which represents the overall effect of annual and daily temporal segregation. The dendrogram concisely shows the result of hierarchical clustering of the complex pairwise total overlap indexes (Figure 6 ). The species within the same group tend to have similar activity patterns. As shown in Figure 6, the nine species were clustered into 3 large branches, namely, livestock, blue sheep, and the carnivores. As expected, herbivores avoid predation by large carnivores by staggering their presence at this site. Then there are two apparent clusters under the carnivore branch, one composed of brown bears, Pallas's cats, snow leopards, and the two fox species; and the other of gray wolves and domestic dogs. Wolves occasionally kill dogs, but they were clustered together. The three main large carnivores, those with the greatest potential conflict-snow leopard, 
wolf, and brown bear-were grouped into different clusters, showing that they might have developed a mechanism to avoid conflicts, especially the wolf and the snow leopard. Thus, the degree of segregation may relate to the position of species in the food chain, from herbivores, small carnivores to large carnivores, as well as to body size.

\section{Conclusions}

In summary, using camera traps, we identified an important marking site or sign post used by snow leopards and several sympatric species for intra- and interspecies communication. We introduced the Schoener index and clustering dendrogram to measure and represent the degree of temporal segregation between species photographed and found that they were temporally segregated more or less at this location, presumably to avoid direct confrontations. Such a communal sign post provided preliminary knowledge of the finer-scaled habitat use of snow leopards and of niche segregation between species, an important consideration for protecting key habitats of snow leopards and other sympatric mammals. Future research could locate and investigate other such sites in order to learn how intraspecies and interspecies communications are conducted, as well as understanding the community structures and role of snow leopards in the ecosystem.

\section{Conflict of Interest}

We certify that there is no conflict of interest in this paper.

\section{Acknowledgments}

This study was a preliminary effort of a larger snow leopard research and conservation project jointly conducted by Qinghai Forestry Department, Shan Shui Conservation Center, the Center for Nature and Society of Peking University, and the Panthera and the Snow Leopard Trust. The authors thank Tudengzhaxi, Angye, Nangcaicicheng, Naobowending, Bairang, and others from Sub-Gongsa Monastery; and Lan $\mathrm{Wu}$, Lingyun Xiao, and Meiqi Liu from Peking University for their assistance in the field work. Others contributed to the project, among them Hang Yin, Haiyuan Ma, Dawajiangcai, and Zhaxiduojie. They also extend their special appreciation to Sandan Li, Li Zhang, Yu Zhang of the Qinghai Forestry Department and Ruofan Li, Renzeng, and others from Qinghai Sanjiangyuan Nature Reserve.

\section{References}

[1] R. M. Jackson, D. Mallon, T. McCarthy, R. A. Chundaway, and B. Habib, "Panthera uncia," in IUCN, 2011: IUCN Red List of Threatened Species, Version 2011. 2, 2008.

[2] T. M. McCarthy and G. Chapron, Snow Leopard Survival Strategy, ISLT and SLN, Seattle, Wash, USA, 2003.

[3] Y. V. Bhatnagar, V. B. Mathur, and T. McCarthy, "A regional perspective for snow leopard conservation in the Indian TransHimalaya," in Contributed Papers to the Snow Leopard Survival
Strategy Summit, T. McCarthy and J. Weltzin, Eds., pp. 25-47, International Snow Leopard Trust, Seattle, Wash, USA, 2002.

[4] R. M. Jackson and G. Ahlborn, "A preliminary habitat suitability model for the snow leopard (Panthera uncia)," in International Pedigree Book of Snow Leopards, vol. 4, pp. 43-52, 1984.

[5] M. Wolf and S. Ale, "Signs at the top: habitat features influencing snow leopard Uncia uncia activity in sagarmatha national park, nepal," Journal of Mammalogy, vol. 90, no. 3, pp. 604-611, 2009.

[6] G. B. Schaller, R. Junrang, and Q. Mingjiang, "Status of the snow Leopard Panthera uncia in Qinghai and Gansu Provinces, China," Biological Conservation, vol. 45, no. 3, pp. 179-194, 1988.

[7] S. Bagchi and C. Mishra, "Living with large carnivores: predation on livestock by the snow leopard (Uncia uncia)," Journal of Zoology, vol. 268, no. 3, pp. 217-224, 2006.

[8] T. Sangay and K. Vernes, "Human-wildlife conflict in the Kingdom of Bhutan: patterns of livestock predation by large mammalian carnivores," Biological Conservation, vol. 141, no. 5, pp. 1272-1282, 2008.

[9] K. Rails, "Mammalian scent marking," Science, vol. 171, no. 3970, pp. 443-449, 1971.

[10] J. F. Eisenberg and D. G. Kleiman, "Olfactory communication in mammals," Annual Review of Ecology and Systematics, vol. 3, pp. 1-32, 1972.

[11] R. M. Jackson, Home range, movements and habitat use of snow Leopard (Uncia uncia) in Nepal [Ph.D. thesis], University of London, London, UK, 1996.

[12] R. R. Swaisgood, D. G. Lindburg, A. M. White, Z. Hemin, and Z. Xiaoping, "Chemical communication in giant pandas: experimentation and application," in Giant Pandas: Biology and Conservation, D. G. Lindburg and K. Baronga, Eds., pp. 106-120, Oxford University Press, Oxford, UK, 2004.

[13] T. L. Burst, "Black bear mark trees in the Smoky Mountains," in Proceedings of the International Conference on Bear Research and Management, vol. 5, pp. 45-53, 1983.

[14] A. M. White, R. R. Swaisgood, and H. Zhang, "Chemical communication in the giant panda (Ailuropoda melanoleuca): the role of age in the signaller and assessor," Journal of Zoology, vol. 259, no. 2, pp. 171-178, 2003.

[15] T. W. Schoener, "Resource partitioning in ecological communities," Science, vol. 185, no. 4145, pp. 27-39, 1974.

[16] Y. Liao, "The geographical distribution of ounces in Qinghai Province," Acta Theriologica Sinica, vol. 5, pp. 183-188, 1985.

[17] D. P. Mallon, "Research, survey and biodiversity planning on the Tibet-Qinghai Plateau, China," Final Report For Darwin Initiative For the Survival of Species, 2004.

[18] S. Li, W. J. Mcshea, D. Wang, L. Shao, and X. Shi, "The use of infrared-triggered cameras for surveying phasianids in Sichuan Province, China," Ibis, vol. 152, no. 2, pp. 299-309, 2010.

[19] T. G. O’Brien, M. F. Kinnaird, and H. T. Wibisono, "Crouching tigers, hidden prey: Sumatran tiger and prey populations in a tropical forest landscape," Animal Conservation, vol. 6, no. 2, pp. 131-139, 2003.

[20] T. W. Schoener, "The Anolis lizards of Bimini: resource partitioning in a complex fauna," Ecology, vol. 49, pp. 704-726, 1968.

[21] R Development Core Team, $R$ : A language and Environment for Statistical Computing, R Foundation for Statistical Computing, Vienna, Austria, 2011.

[22] G. B. Schaller, Mountain Monarchs: Wild Sheep and Goats of the Himalaya, University of Chicago Press, Chicago, Ill, USA, 1977. 
[23] G. I. Green and D. J. Mattson, "Tree rubbing by yellowstone grizzly bears Ursus arctos," Wildlife Biology, vol. 9, no. 1, pp. 1-9, 2003.

[24] R. P. Peters, "Scent-marking in wolves: radio-tracking of wolf packs has provided definite evidence that olfactory sign is used for territory maintenance and may serve for other forms of communication within the pack as well," American Scientist, vol. 63, pp. 628-637, 1975.

[25] I. Barja, F. J. De Miguel, and F. Bárcena, “The importance of crossroads in faecal marking behaviour of the wolves (Canis lupus)," Naturwissenschaften, vol. 91, no. 10, pp. 489-492, 2004.

[26] G. A. Polis, C. A. Myers, and R. D. Holt, "The ecology and evolution of intraguild predation: potential competitors that eat each other," Annual review of ecology and systematics, vol. 20, pp. 297-330, 1989.

[27] F. Palomares and T. M. Caro, "Interspecific killing among mammalian carnivores," American Naturalist, vol. 153, no. 5, pp. 492-508, 1999.

[28] N. Kronfeld-Schor and T. Dayan, "Partitioning of time as an ecological resource," Annual Review of Ecology, Evolution, and Systematics, vol. 34, pp. 153-181, 2003.

[29] L. D. Mech and L. Boitani, Wolves: Behavior, Ecology, and Conservation, University of Chicago Press, Chicago, Ill, USA, 2003.

[30] J. Naves, A. Fernández-Gil, C. Rodrìguez, and M. Delibes, "Brown bear food habits at the border of its range: a long-term study," Journal of Mammalogy, vol. 87, no. 5, pp. 899-908, 2006.

[31] S. B. Merrill and L. David Mech, "The usefulness of GPS telemetry to study wolf circadian and social activity," Wildlife Society Bulletin, vol. 31, no. 4, pp. 947-960, 2003.

[32] M. Unit, "Daily patterns and duration of wolf activity in the Bialowieza forest, Poland," Journal of Mammalogy, vol. 84, pp. 243-253, 2003. 

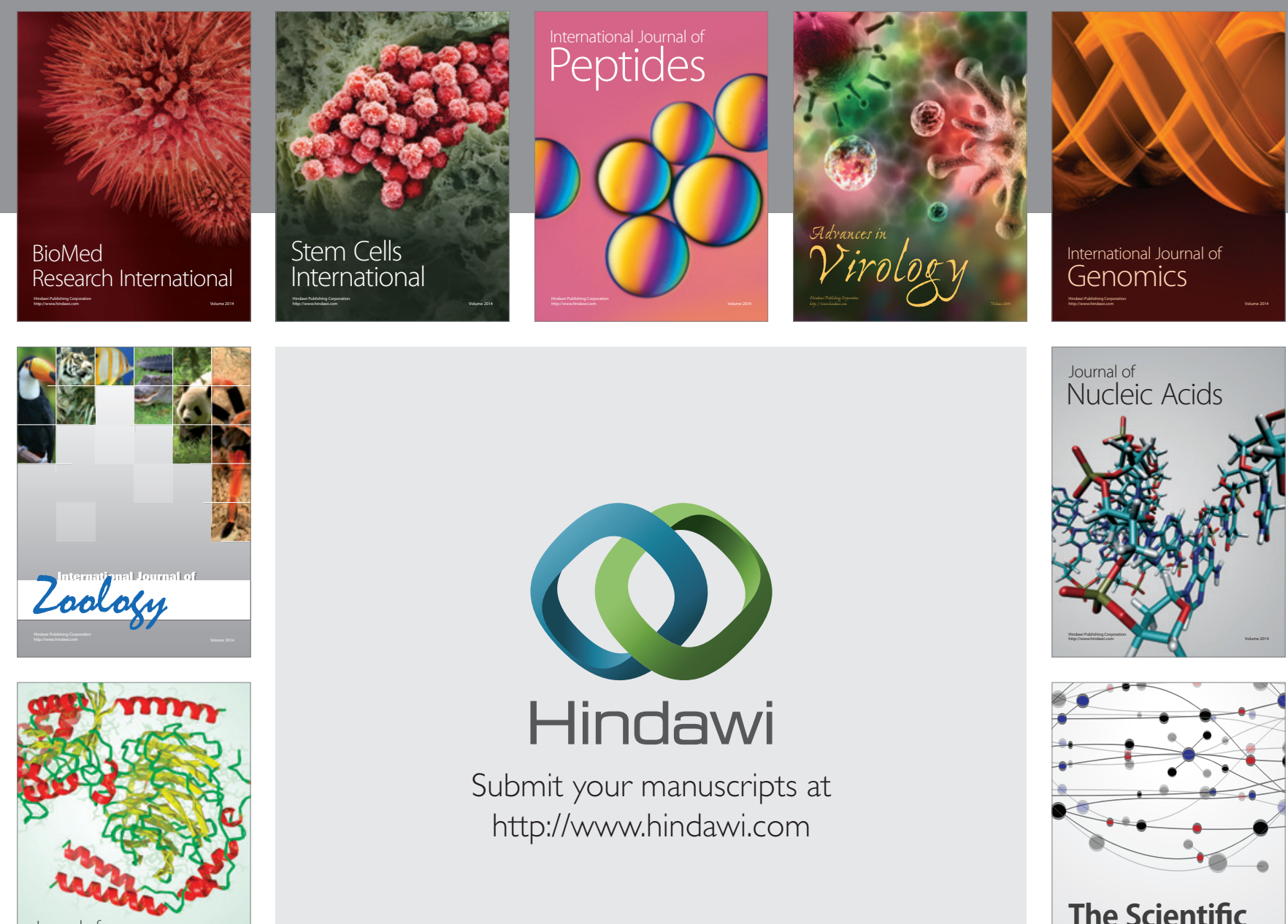

Submit your manuscripts at

http://www.hindawi.com

Journal of
Signal Transduction
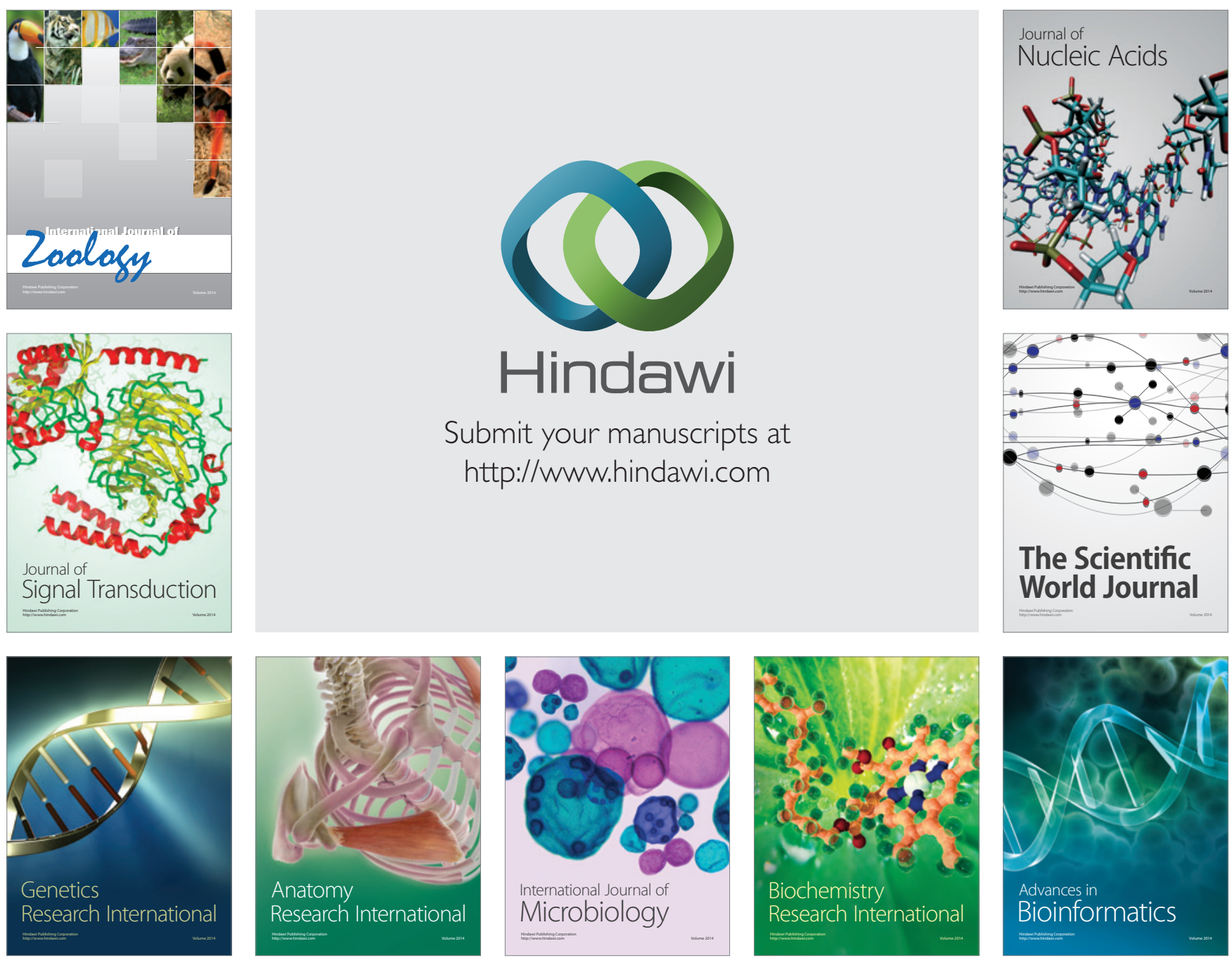

The Scientific World Journal
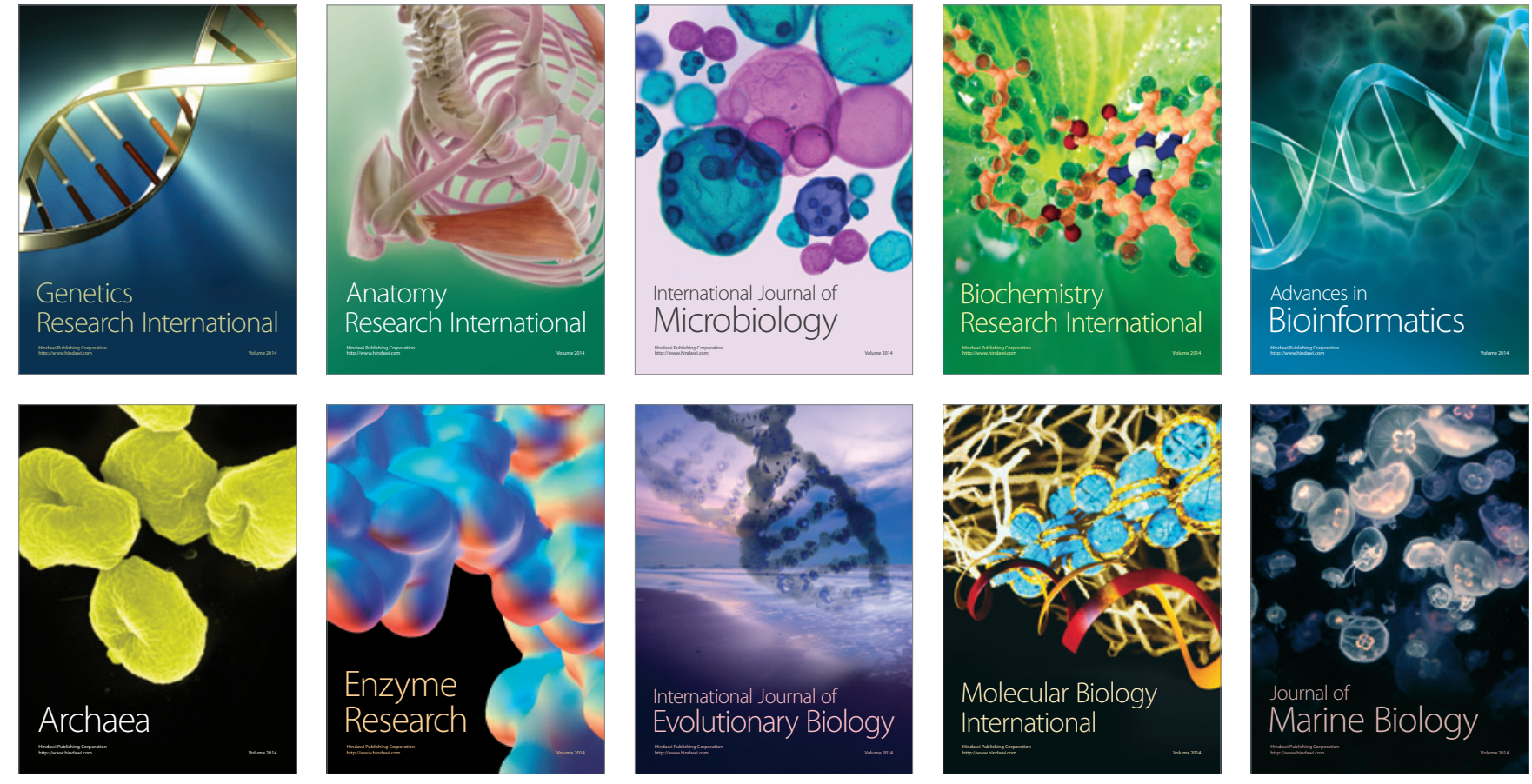